\title{
Retrosigmoid Approach to the Posterior Fossa Trigeminal Schwannoma
}

\author{
Alexander Yang ${ }^{1}$ Katherine Kunigelis ${ }^{1} \quad$ A. Samy Youssef ${ }^{1}$ \\ ${ }^{1}$ Department of Neurosurgery, University of Colorado, Aurora, \\ Colorado, United States \\ J Neurol Surg B 2018;79(suppl S5):S393-S394.

\begin{abstract}
Address for correspondence A. Samy Youssef, MD, PhD, Department of Neurosurgery, University of Colorado Anschutz Medical Campus, 12631 East 17th Avenue, Box C307, Aurora, CO 80045,
\end{abstract} \\ United States (e-mail: Samy.Youssef@UCDenver.edu).
}

\begin{abstract}
Keywords

- posterior fossa

- schwannoma

- trigeminal

- nerve preservation

- retrosigmoid

We present a case of a posterior fossa trigeminal schwannoma in a 31-year-old gentleman. Preoperative symptomatology included headaches and dizziness of 6 months in duration. Trigeminal schwannomas isolated to the posterior fossa, not extending into Meckel's Cave, may be adequately resected via a retrosigmoid approach. Thus, a tailored retrosigmoid approach was planned with navigation assistance. A key point to highlight is the difficult identification and preservation of trigeminal nerve fascicles within the tumor mass. In this operative video we show a nerve preservation technique. By identifying the nerve at the anticipated anatomical location and utilizing sharp dissection, we create a dissection plane from the nerve fascicles. The surgical strategy of near total resection and leaving minimal tumor tissue on the nerve should be pursued in return for anatomical preservation of the nerve. Postoperative course was significant for facial hypoesthesia, abducens partial palsy, and gradual improvement of headaches.

The link to the video can be found at: https://youtu.be/JsE1-Eonr0k.
\end{abstract}

Conflict of Interest

None.

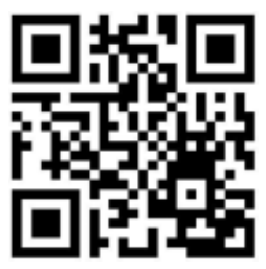

received

April 28, 2018

accepted

August 12, 2018

published online

September 25, 2018

www.thieme.com/skullbasevideos

www.thieme.com/jnlsbvideos
DOI https://doi.org/

10.1055/s-0038-1669976. ISSN 2193-6331.
๑) 2018 Georg Thieme Verlag KG
Stuttgart · New York

License terms

() (i) $\ominus$ (\$) 


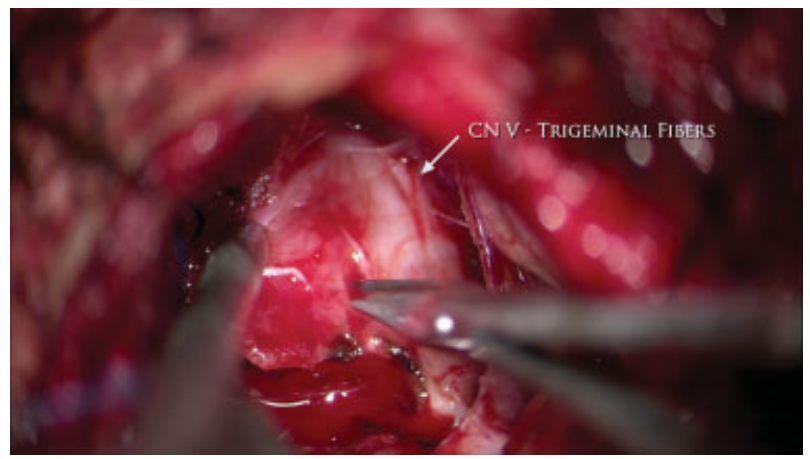

Fig. 1 Identification of trigeminal nerve fibers and demonstration of nerve preservation, sharp dissection technique.

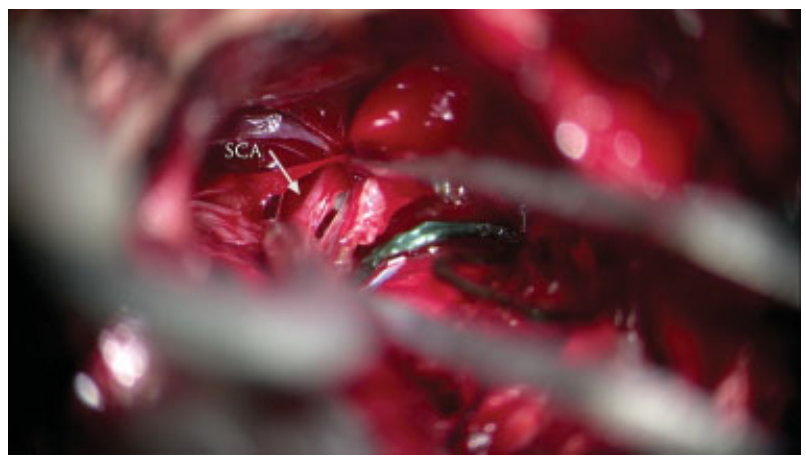

Fig. 2 An example of identification and preservation of critical vascular structures such as the Superior Cerebellar Artery (SCA) that had anatomical deviation due to the presence of the mass. 